\title{
Física aplicada: apoyo al combate de la pandemia COVID-19
}

\author{
Héctor Hugo Cerecedo Núñez y Patricia Padilla Sosa
}

\section{Resumen}

La física se basa en dos pilares fundamentales para su ejercicio, la teoría y la experimentación, ambas son complementarias. En la experimentación física se descubren nuevos fenómenos; en ella, también se comprueban los resultados que la teoría indica o predice.

Actualmente, el mundo entero vive una contingencia sanitaria por el surgimiento del virus SARS-CoV-2, causante de la enfermedad covid-19. Por ello, se busca comprender su origen, composición o estructura, las formas de contagio o de propagación, así como tener un control de su mecanismo, y encontrar una posible cura.

La física aplicada, con sus resultados, pruebas experimentales, aplicación de métodos y conceptos, están apoyando el entendimiento de este virus y el combate en su contra.

Palabras clave: física aplicada, biofísica, virus, SARS-CoV-2, COVID-19.

\section{Applied Physics: support for fighting the COVID-19 PANDEMIC}

\begin{abstract}
Physics is based on two fundamental pillars for its exercise, theory, and experimentation, both are complementary. New phenomena are discovered in physical experimentation; in it, the results that theory indicates or predicts are also verified.

Currently, the whole world is experiencing a health emergency due to the appearance of SARS-CoV-2 virus, which causes covid-19 disease. Therefore, we seek to understand his origin, composition or structure, ways of contagion and spread, as well as having control of its mechanism and find a possible cure.

Applied physics, with its results, experimental tests, application of methods and concepts, is supporting the understanding of this virus and the fight against it.
\end{abstract}

Keywords: applied physics, biophysics, virus, SARS-COV-2, COVID-19.

Recepción: 8/09/2020. Aprobación: 25/01/2021.

Dol: http://doi.org/10.22201/cuaieed.16076079e.2021.22.2.6 
Google Scholar: H. H. Cerecedo-Núñez researchgate.net/profile/H_Cerecedo-Nunez Laboratorio de óptica aplicada UV

Licenciatura en Física (Facultad de Física, Universidad Veracruzana), posdoctorado en el Instituto Tecnológico de Virginia (Blacksburg, VA, USA). Actualmente es investigador y profesor en la Facultad de Física de la Universidad Veracruzana. Desarrolla actividades en el área de Óptica Aplicada, en diversos proyectos relacionados con fotónica, biofotónica, sensores y monitoreo de parámetros físicos con luz. Cofundador del Laboratorio de Óptica Aplicada de su entidad de adscripción. Ha participado en varios proyectos de investigación y académicos, en los cuales se han logrado obtener recursos económicos para infraestructura de laboratorios de enseñanza e investigación. Ha publicado artículos en revistas indizadas, en memorias en extenso y capítulos en libros (arbitrados y relacionados con física y óptica aplicada).

\section{Patricia Padilla Sosa}

ppadilla@uv.mx

\section{Google Scholar Citations: Patricia Padilla Sosa researchgate.net/profile/Patricia_Padilla-Sosa Laboratorio de óptica aplicada UV}

Licenciatura en física, con doctorado en Ciencias con especialidad en Óptica, actualmente académica de la Universidad Veracruzana, Facultad de Física. Coordinadora y colaboradora del cuerpo académico de óptica aplicada y materia condensada blanda. Cofundadora del Laboratorio de Óptica Aplicada de la misma entidad de adscripción. 


\section{Introducción}

La física es una rama esencial de las ciencias, que estudia los componentes fundamentales del universo. Comprende el estudio de la materia, la energía, el espacio-tiempo, las interacciones fundamentales; sus leyes y la relación en entre todo ello, así como sus aplicaciones en la humanidad (lo que denominamos física aplicada).

La física aplicada, al igual que otras muchas disciplinas importantes, está contribuyendo directa o indirectamente en la solución y entendimiento de la emergencia sanitaria del virus SARS-CoV-2, causante de la enfermedad covi-19 (Velavan y Meyer, 2020).

La física en general se ocupa de innumerables fenómenos naturales. Por ello es conveniente mencionar que, para su estudio, compresión o entendimiento, se intenta identificar esos fenómenos de acuerdo con divisiones, ramas o teorías. Así, por un lado, las divisiones de la física son la física teórica, que se apoya de fundamentos matemáticos para explicar, con leyes y teorías, el comportamiento de la naturaleza; la física computacional, que con el apoyo de la programación y algoritmos computacionales modela la naturaleza física; y física experimental y aplicada, que basa las investigaciones en el desarrollo de experimentos, pruebas y prototipos, con un enfoque útil o práctico.

Por otro lado, las ramas de la física son la física clásica, basada en conceptos y teorías desarrollados hasta el siglo xix; la física moderna, que parte de la postulación de la cuantización de la energía, a inicios del siglo xx; la física contemporánea, que considera conceptos y teorías actuales, que, incluso, inciden en otras áreas como biología, medicina, ingenierías, etcétera, y que también podríamos considerar como física multidisciplinaria.

Imagen 1. Estructura de SARSCoV-2. Modificada de CDC, Eckert y Higgins (2020). Además, para la física, las teorías que rigen la naturaleza se encuentran en la mecánica clásica, electromagnetismo, termodinámica y mecánica estadística, mecánica cuántica y relatividad; en las cuales, se incluyen innumerables fenómenos y conceptos.

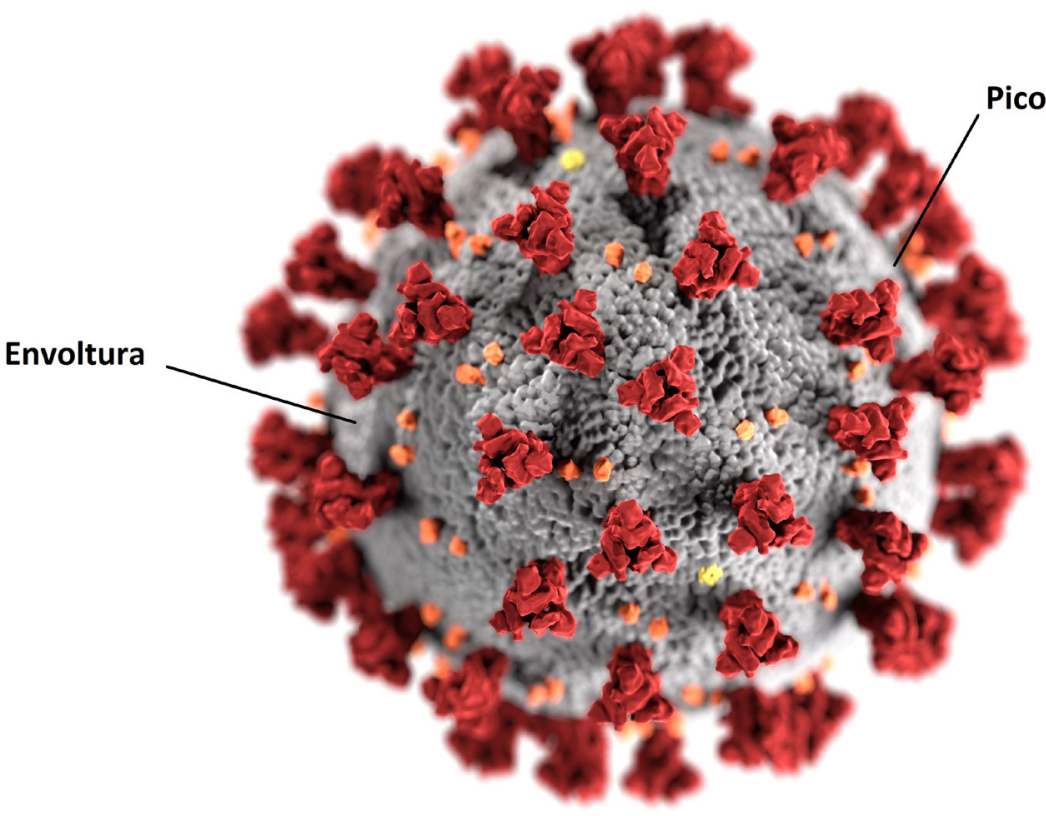

Durante la descripción de este trabajo haremosreferenciaaalgunas deesasteorías, fenómenos y conceptos, con la finalidad de queellectoridentifiqueesas ramas delafísica con el problema que se está analizando. De este modo, explicaremos, con investigación documentada, la relación existente con la estructura del virus, la detección indirecta o su monitoreo, la propagación, la forma de controlarlo o evitarlo, así como algunas formas de erradicarlo.

\section{El virus y la física moderna}

Un virus, como el sARS-cov-2, presenta una estructura molecular mucho más pequeña que una célula (ver imagen 1). Los virus 
Imagen 2. Microscopio de transmisión de electrones (Ortisa, 2010).

Imagen 3. Partículas virales de SARS-CoV-2 que emergen de cultivos celulares. Obtenida con un microscopio de transmisión de electrones (NIAID, 2020).

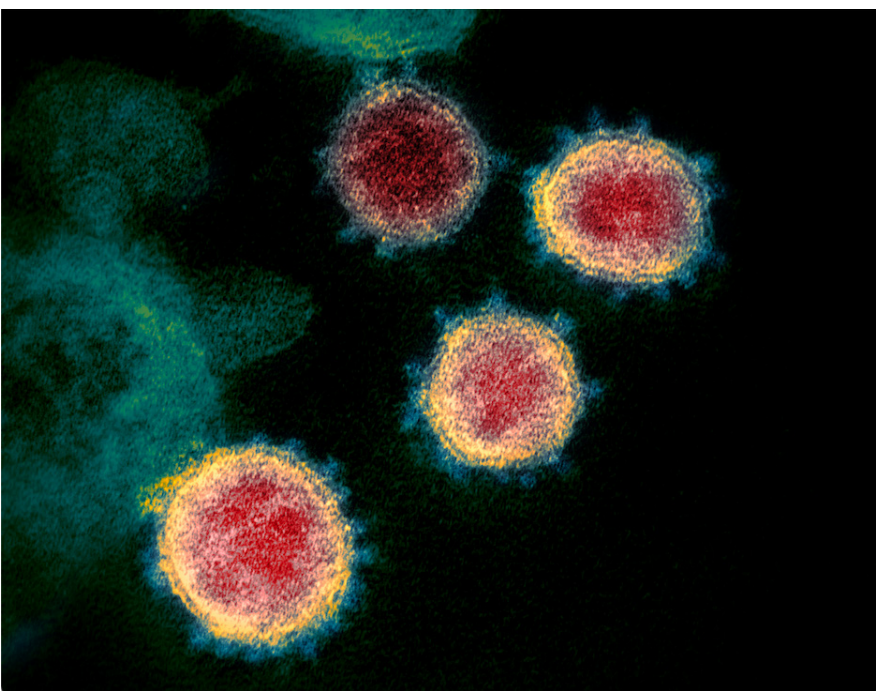

tienen un diámetro aproximado entre 50 a 200 nm (un nanómetro —nm— equivale a una mil millonésima parte de un metro: $1 \mathrm{~nm}=10^{-9} \mathrm{~m}$ ). Por esa razón, no es posible visualizarlo con un microscopio convencional, que emplea luz y fotones. Para ello, se requiere un equipo más poderoso; en este caso un microscopio de transmisión de electrones (TEM: Transmission Electron Microscopy; Winey et al., 2014). Un instrumento de este tipo emplea un haz de electrones, que se concentra en un área muy pequeña (se enfoca), e incide sobre la muestra y la atraviesa (ver imagen 2).

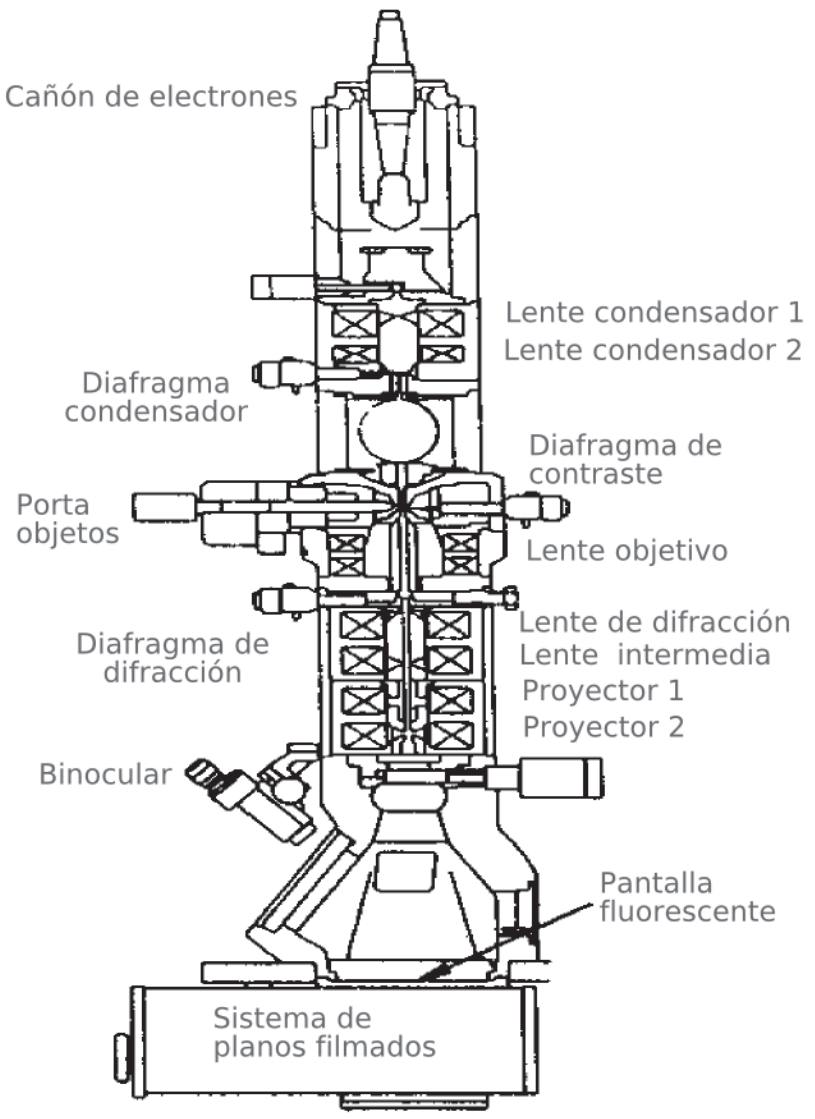

Además de lograr ver al virus, podemos conocer partes de su estructura interna y externa, con apoyo de técnicas similares a TEM (ver imagen 3), como la microscopía criogénica de electrones (cryo-em: Cryogenic Electron Microscopy), en la que la muestra se coloca a muy bajas temperaturas. También existe la microscopía de escaneo de electrones (SEM: Scanning Electron Microscope), la cual es una técnica de monitoreo superficial. Los microscopios de electrones actuales son el resultado de los estudios de los físicos sobre los electrones y su comportamiento con la materia. Estos conocimientos ahora son esenciales en la física moderna y contemporánea. 


\section{La detección y la óptica}

El procedimiento estándar para el diagnóstico del virus se realiza por medio del método de reacción de cadena de polimerasa (PCR, Polymerase Chain Reaction). En él, la muestra a investigar — saliva, por ejemplo_ pasa a través de varios ciclos químicos y en la última etapa se emplea un arreglo óptico, que determina si la muestra es positiva o no al virus. Así, la muestra ya procesada, se coloca en ese instrumento óptico, y se realiza una medición de emisión de radiación fluorescente para el diagnóstico final. El arreglo óptico que se emplea consiste en una lámpara de tungsteno (como los focos convencionales), filtros de color, espejos y una cámara digital para el procesamiento de la intensidad de la luz (Sreejith et al., 2018). Las áreas de la física moderna (física contemporánea) y la óptica, proporcionan los conocimientos físicos para comprender cómo se lleva a cabo el diagnóstico.

\section{Monitoreo del virus, física del estado sólido y la luz}

Aunque no existe una forma directa de monitorear la presencia de un virus, para el caso del SARS-CoV-2 y su enfermedad CovID-19, esto se puede realizar de una forma indirecta, apoyándonos de algunos instrumentos. Entre ellos se encuentran los termómetros de radiación infrarroja y los oxímetros portátiles. Ambos instrumentos operan con principios de la física del estado sólido, relacionado con la física de los materiales, y del espectro electromagnético, vinculados con la radiación infrarroja, o sea, la energía calorífica que se encuentra entre los $800 \mathrm{~nm}$ a $1 \mathrm{~mm}$.

Por ejemplo, el termómetro de pistola es un sensor puntual, que tiene un detector semiconductor ${ }^{1}$ de radiación infrarroja, calibrado para los rangos de temperatura humana. También cuenta con un apuntador láser, pero eso únicamente sirve para indicar el punto donde se medirá la temperatura. Este tipo de termómetros sólo permite conocer la temperatura de una persona, cuyo rango normal va de 36.1 a $37.2^{\circ} \mathrm{C}$ (U.S. National Library of Medicine, 2020); e informa si el individuo se encuentra fuera de lo normal (arriba de $38^{\circ} \mathrm{C}$ ), lo cual puede ser un indicador de la presencia de algún virus o infección, dentro de su cuerpo. Por cierto, este tipo de termómetros no daña la salud, su radiación es completamente segura (en los puntos indicados) para el ser humano.

En el caso del oxímetro, éste funciona con la ayuda de un detector semiconductor de radiación y una fuente de emisión de luz infrarrojos (por ejemplo, un diodo láser, LED). La luz debe atravesar un dedo de la mano y con ello

${ }^{1}$ Un semiconductor es un material que presenta una conductividad eléctrica, cuyo valor se encuentra entre el de los metales y los aislantes. se miden las variaciones de esta radiación, la cual esta calibrada para conocer la oxigenación y el pulso del paciente. En el caso de la pandemia que nos atañe, es útil para el monitoreo de la irrigación de oxígeno dentro de nuestro cuerpo, ya que ello es un parámetro determinante de la evaluación de la enfermedad. 


\section{La propagación del virus y la luz}

Aun que el virus es muy pequeño (ya hemos mencionado que no lo podemos ver a simple vista o con algún instrumento óptico convencional), es posible "visualizar" indirectamente, o al menos tener una idea, cómo se propaga por contacto o a través del aire.

La luz resulta una herramienta útil para comprender la amplia y rápida propagación de secreciones, en este caso, por gotas de saliva, que contienen virus. Existen experimentos en los que se ha empleado luz ultravioleta para visualizar la propagación por contacto; así como arreglos ópticos clásicos con luz convencional y arreglos láseres para visualizar la propagación de gotas de saliva de tamaño microscópico en el aire, conocidas como gotículas o microgotas, que son pequeñas gotas de saliva de tamaño microscópico.

Se han reportado experimentos cualitativos que permiten visualizar indirectamente la propagación del virus, a través de la diseminación por contacto (Rober, 2020; NHK WORLD-JAPAN, 2020c). En ellos se emplean polvos y pinturas fluorescentes, que son incoloros a simple vista, como el virus, y se aplican a una o a varias personas, para observar su propagación. En ambos casos, un solo individuo toma un poco de pintura fluorescente y la frota en sus manos. Posteriormente, se le ingresa a un cuarto con iluminación convencional, en el que hay un grupo de personas (15 aproximadamente). Después de un determinado tiempo (en promedio 30 minutos), tras llevar a cabo actividades normales, se realiza una inspección con iluminación ultravioleta. El resultado revela la propagación de los polvos o la pintura fluorescente hacia los integrantes del convivio y su presencia en los diversos objetos e instrumentos que se tocaron.

Para estudiar la manera en que los virus pueden propagarse en el aire, se visualiza el flujo de gas que expulsa nuestro cuerpo (lo que incluye las gotículas), bajo diferentes condiciones, al toser. Con ello se comprueba la efectividad del uso de mascarillas. El experimento fue realizado en la Bauhaus-Universität Weimar de Alemania. En él, se emplea un arreglo óptico clásico, conocido como sistema de contraste de fase, para visualizar cambios de densidad del aire (también es conocido como sistema Schlieren o sistema de shadowgraphy). Dicho arreglo utiliza un espejo cóncavo circular, iluminación láser y una cámara digital (Settles et al., 1995; Völker, 2020). Cabe destacar que estas pruebas están relacionadas también con conceptos de la física de los fluidos.

En otro caso muy similar al anterior, se observa la transmisión y el alcance de las gotículas de saliva, transportadoras de virus, a través del aire y en ambientes cerrados, al momento de hablar o estornudar. Estos estudios se apoyan de la implementación de una hoja de luz láser, que son planos de luz formados con uno o varios haces de luz láser, y una cámara de alta sensibilidad (Ala Bouhanguel, 2011; NHK WORLD-JAPAN, 2020a). En un cuarto de laboratorio acondicionado, se realizan varias pruebas, haciendo que una persona estornude 
Video 1. Experimento sobre la manera en la que el SARS-CoV-2 se propaga al hablar (cNn Chile, 2020). y que, posteriormente, se encuentre en una situación de plática con otra. El ambiente alrededor está iluminado adecuadamente con la luz láser, lo cual permite visualizar las microgotas de saliva (que se encuentran entre un milímetro y 0.1 micrómetros de diámetro) y con ello determinar su alcance. Con estos datos y ayuda de la física computacional también se pueden realizar simulaciones que predicen la propagación y el alcance de las gotículas en diferentes ambientes o espacios (ver video 1).

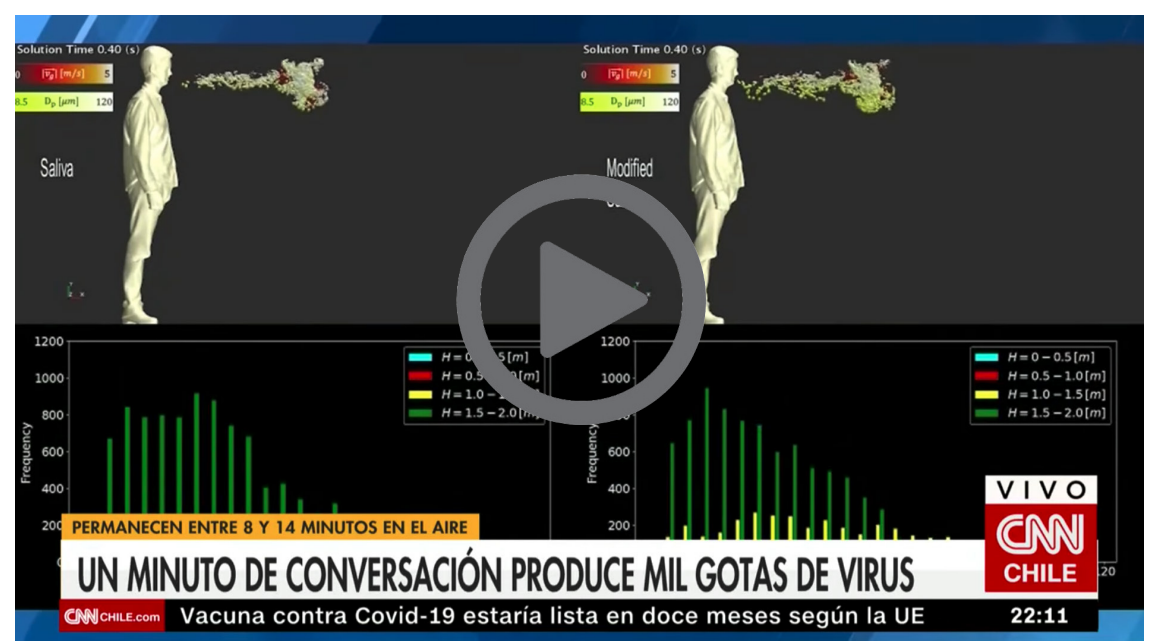

Como se puede observar de los casos anteriores, los conocimientos de fluorescencia, láseres y óptica son fundamentales para platear y comprender este tipo de fénomenos. Los conceptos necesarios los proporciona la física clásica y la física moderna.

También queda claro que, empleando conceptos fundamentales de mecánica clásica, como la distancia y el tiempo, y apoyados con cultivos bacteriales, es posible conocer las diferentes dosis de bacterias (y en este caso de virus) que una persona puede expulsar al toser o estornudar (cBs 8 San Diego, 2020; Youtube PIDC, 2020). Ello se logra con una especie de experimentos de alcance por tiro parabólico, como los que se estudian en la mecánica clásica. Para este caso, se coloca a una persona y se le pide que estornude, que hable o que tosa. Los fluidos que salgan de su boca serán los proyectiles. En frente de esa persona se colocan cajas de Petri (para cultivo), preparadas para recibir las gotículas expulsadas. Así, es posible estudiar la cinemática de las partículas a partir de la trayectoria parabólica que siguen. Dicho conocimiento es útil para tomar medidas de prevención.

\section{Cómo evitar al virus mediante la física}

Mucho se ha comentado que el lavado de manos con jabón es muy importante para evitar el contagio por contacto, al igual que el uso de gel antibacterial (con contenido de alcohol). En el caso del lavado con agua y jabón, la física también ha contribuido en el desarrollo y entendimiento de ello. Aquí, la explicación entra 
Video 2. ¿Cómo destruye el lavado de manos a los virus? (Imagen Noticias, 2020).

${ }^{2}$ El hielo seco es una especie de vapor o humo de una sustancia no tóxica. en el ámbito de la fisicoquímica, que explica el mecanismo de operación de la aniquilación del virus. Para ello existen experimentos cualitativos y demostrativos (RCSBProteinDataBank, 2020; Vox, 2020). En ellos, se resume y explica un experimento sencillo entre agua, jabón y aceite. Lo primero que debemos saber es que las moléculas de jabón y aceite (que equivale a la emulación de un virus) son distintas, y cuentan con cargas (polaridades) diferentes, cargas positivas $(+)$ y negativas (-). De esta manera, un extremo de las moléculas de jabón, con cargas positivas, se adhiere a las moléculas que conforman el virus. El otro extremo, con cargas negativas, se adhiere a las moléculas de agua. Ésta juega un papel importante, pues sus moléculas ayudan en la destrucción del virus (ver video 2). Como se ha indicado, todo ello tiene lugar debido a las distintas cargas y a la atracción electrostática que presentan las diferentes moléculas en cuestión. Estos conceptos son fundamentales en electrostática, teoría electromagnética, fisicoquímica, entro otros.

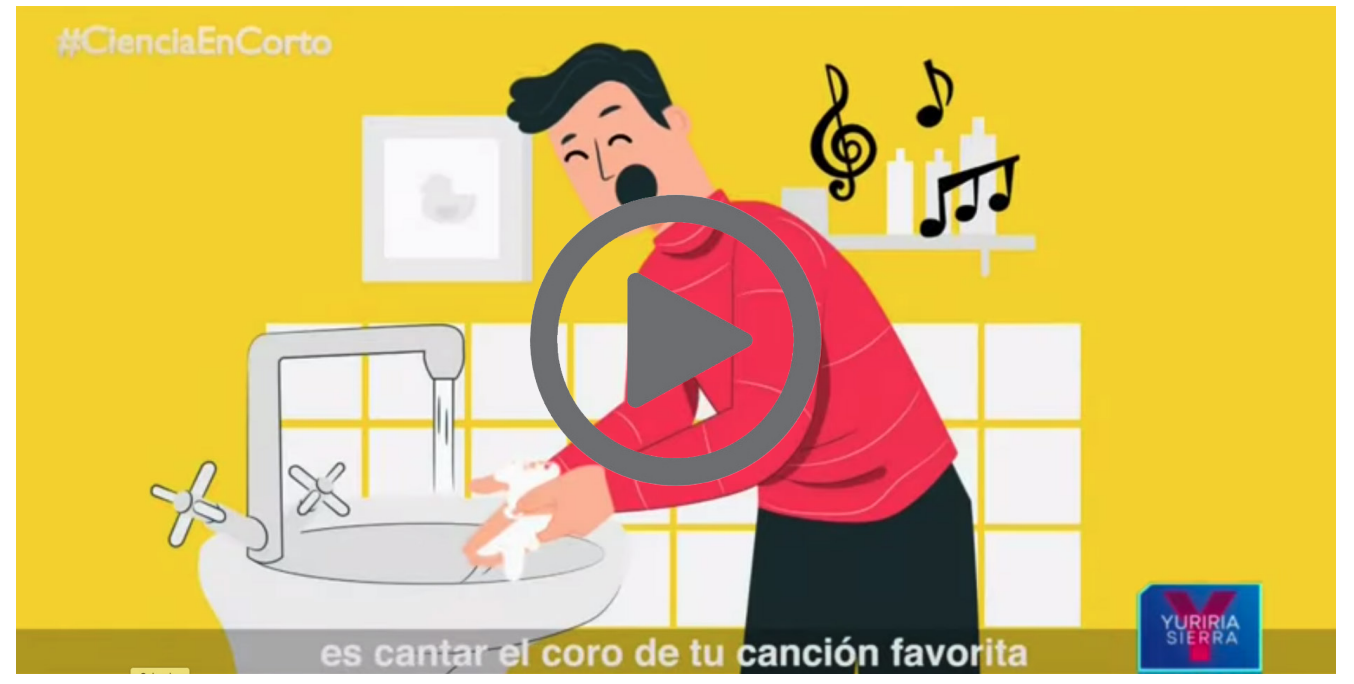

Recientemente, en México, surgió una manera ingeniosa de evitar el contacto directo en pequeñas tiendas de productos básicos. Para ello se echa mano de conceptos básicos de la mecánica clásica (Milenio Noticias, 2020). Aprovechando la atracción gravitacional y conceptos fundamentales de mecánica, se han elaborado mecanismos simples para trasportar productos y dinero; por ejemplo, en una tortillería, se colocó una rampa de madera (de más de un metro de largo) para entregar los kilogramos de tortilla. En esa misma tortillería, se colocaron dos rampas de tubos de plástico (Pvc) cortados a lo largo, uno para la entrega del dinero de compra y la otra para entregar el cambio del dinero. De esa forma, se espera reducir el contagio por contacto directo.

Respecto al comportamiento de los flujos de aire, con gotículas portadora de virus, también existen arreglos y experimentos ópticos, que emplean planos $u$ hojas de luz láser, que se forman a partir de un láser y se visualizan con hielo $\operatorname{seco}^{2}$ (NHK WORLD-JAPAN, 2020b). En esos experimentos, se emplean los planos de luz láser para "iluminar" el flujo de aire dentro de una habitación ventilada o 
no, y observar cómo se mueven, lo que permite concluir la importancia de contar con espacios ventilados. Esos experimentos y pruebas también son útiles para el desarrollo de simulaciones computacionales físicas, ya que con ellos se pueden validar modelos físicos teóricos y realizar predicciones del comportamiento de los gases en espacios cerrados o ventilados. Esto, a la vez, nos permite conocer la posición adecuada de los flujos de aire con micropartículas (gotículas). En este caso, los conceptos en láseres, fluidos y óptica son fundamentales.

\section{Acabar con el virus y la radiación electromagnética}

Por el momento no existe una manera efectiva de combatir la enfermedad una vez que se contrae, aunque ya hay vacunas de distribución limitada y algunos tratamientos y medicamentos de prueba. Por ello, sigue siendo importante mantener desinfectados los objetos, instrumentos y áreas comunes de trabajo. Una de las opciones para alcanzar dicho objetivo tiene que ver con el empleo de radiación ultravioleta (en este caso, luz ultravioleta del tipo uv-C, del orden de 200 nm de longitud de onda), que actúa como germicida desinfectante. La radiación ultravioleta que se emplea daña la estructura interna de los virus (a un nivel molecular, dentro de su envoltura) y de esa forma "los elimina" (ver imagen 4).

\section{Espectro Electromagnético}

Imagen 4. Longitud de onda de la luz uv apropiada para desinfección (La imagen corresponde a una adaptación de la referencia de acceso público: Light Progress, UV-C SOURCES, https://www. lightprogress.it/en/blog/uv-csources_1.html, consultado el 15 de febrero de 2021.).

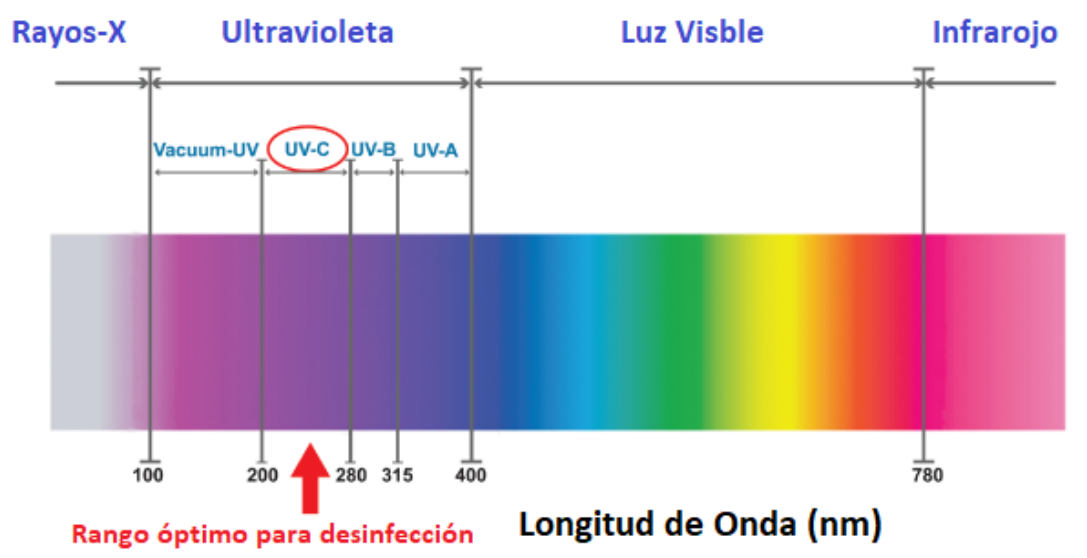

Dicha modalidad es muy bien aceptada en hospitales, para desinfectar superficies e instrumentos (no a los humanos o animales). La radiación ultravioleta que se emplea surge de lámparas, que, con el apoyo de robots, ingresan a las áreas a desinfectar y permanecen encendidas por un corto tiempo (CNBC, 2020). Este tipo de desinfección es muy segura para el ser humano porque no utiliza químicos y reduce el costo laboral. Esta forma de eliminar gérmenes también está siendo utilizada en el interior de aviones comerciales, exterior de autobuses de transporte público y sanitización en hoteles. El futuro de este método de desinfección es muy prometedor. En este caso, conocimientos sobre la interacción de radiación y materia, el espectro electromagnético, luz ultravioleta, entre otros comprendidos en la física moderna, son importantes para el desarrollo de esta aplicación. 


\section{Comentario final}

Al cierre de esta investigación bibliográfica debemos observar que existen muchas otras áreas de la física que también contribuyen en el estudio y comprensión de este virus y su enfermedad, tales como las teorías de redes complejas, estudios de propagación y percolación de la enfermedad, estudios sobre efectos de la movilidad humana, etcétera. (Contoyiannis et al., 2020; Mittal, Ni y Seo, 2020; Ingersoll, 2021; Kaitlynn Snyder et al., 2021; Klanecek, 2021). Sin embargo, por el momento no nos es posible mencionarlos todos.

\section{Conclusiones}

A primera vista, uno podría pensar que la física no es una rama de la ciencia que aporta en el conocimiento y apoyo para la erradicación de una enfermedad como la que estamos viviendo. Sin embargo, hemos podido observar con ejemplos, la forma en que la física fundamental y aplicada contribuye, como una disciplina importante, en el conocimiento y comprensión de padecimientos de salud. Podemos ver cómo las distintas ramas de la física proporcionan conocimientos sobre la propagación, prevención, evasión y erradicación del virus SARS-CoV-2. Así, no debemos perder de vista que tanto la física aplicada junto con otras áreas de las ciencias y tecnología están contribuyendo al combate de este tipo de emergencias médicas.

\section{Referencias}

- Ala Bouhanguel, P. D. (2011). Flow visualization in supersonic ejectors using laser tomography techniques. International Journal of Refrigeration, 34(7), 163301640.

- cBs 8 San Diego. (2020, 1 de julio). How respiratory droplets can spread $\mathrm{u}$ or be stopped [video]. YouTube. https://www.youtube.com/watch?v=slpHCptKZUg

* CDC, Eckert, A. y Higgins D. (2020). SARS-CoV-2 (CDC-23312).png [morfología ultraestructural del nuevo coronavirus 2019]. https://commons.wikimedia.org/ wiki/File:SARS-CoV-2_(CDC-23312).png

* cnBC. (2020, 10 de mayo). How Ultraviolet Light Could Help Stop The Spread Of Coronavirus [video]. YouTube. https://www.youtube.com/watch?v=0J08BuyejuE

* cnn Chile. (2020, 1 de julio). Investigación muestra cómo el coronavirus sars-CoV-2 puede propagarse al hablar [video]. YouTube. https://youtu.be/4JJu5Sesia8

* Contoyiannis, Y., Stavrinides, S. G., Hanias, M. P., Kampitakis, M., Papadopoulos, P., Picos, R. y Potirakis, S. M. (2020). A universal physics-based model describing Covid-19 dynamics in Europe. International Journal of Environmental Research and Public Health, 17(18). Dol: https://doi.org/10.3390/ijerph17186525 
* Settles, G., Hackett, E., Miller, J. y Weinstein, L. (1995, septiembre). Full-Scale Schlieren Flow Visualization. En J. P. Crowder (Ed.), Proc. Intl. Symposium on Flow Visualization, September 11-14, 1995, Seattle, Washington: Flow Visualization vII (pp. 2-13). Begell House.

* Imagen Noticias. (2020, 8 de mayo). ¿Cómo destruye el lavado de manos al Covid-19? | Noticias con Yuriria Sierra [video]. YouTube. https://youtu.be/g2CItabnSwk

* Ingersoll, J. G. (2021). Observations on the Occurrence, Transmission and Management of the covid-19 Pandemic Derived from Physics. Diseases, 9(1), 9. Dol: https://doi.org/10.3390/diseases9010009

* Snyder, K., Quddus, R., Hollingsworth, A. D., Kirshenbaum, K. y Grier, D.G. (2021, 17 de marzo). Holographic Immunoassays: Battling covID-19with Soft Matter Physics. En C. Reichhardt (moderadora), Session P17: Statistical Mechanics of Disease Propagation I. American Physical Society March Meeting 2021. https://meetings. aps.org/Meeting/MAR21/Session/P17

* Sreejith, K. R, Ooi, C. H., Jin, J., Dao, D. V. y Nguyen, N. T. (2018, 4 de diciembre). Digital polymerase chain reaction technology - recent advances and future perspectives. Lab Chip, 18(24), 3717-3732. Dol: https://doi.org/10.1039/c8lc00990b

Klanecek, Z., Naganawa, S., Kim, J., Rivetti, L., Studen, A., Yip, S. S. F. y Robert, J. (2021, 16 de marzo). Performance and Robustness of Machine Learningubased Radiomic covid-19 Severity Prediction. En Session H71: Poster Session I (2:00pm 4:00 pm). American Physical Society March Meeting 2021. http://meetings.aps.org/ Meeting/MAR21/Session/H71.116

* Milenio Noticias. (14 de Mayo de 2020). Tortillería aplica la sana distancia de manera ingeniosa. https://www.youtube.com/watch?v=vTwI9ISI050

* Mittal, R., Ni, R., y Seo, J. (2020, 10 de julio). The flow physics of covid-19. Journal of Fluid Mechanics, 894, F2. Dol: https://doi.org/10.1017/jfm.2020.330

- NHK WORLDIJAPAN. (2020a, 3 de abril). Coronavirus: New Facts about Infection Mechanisms - NHK Documentary [video]. YouTube. https://youtu.be/H2azcn7MqOU

* NHK WORLDDJAPAN. (2020b, 30 de junio). covid-19: Clearing the Air Effectively - NHK Documentary [video]. YouTube. https://youtu.be/59tQeLOehbM

- NHK WORLDuJAPAN. (2020c, 13 de Mayo). covid-19: The Dangers of "HighrTouch Surfaces" - NHK Documentary [video]. YouTube. https://youtu.be/oB9mAgicwAg

* NIAID. (2020, 12 de febrero). Novel Coronavirus SARs-CoV-2.png [imagen de sarsCoV-2 obtenido con un microscopio de transmisión de electrones]. https:// commons.wikimedia.org/wiki/File:Novel_Coronavirus_SARS-CoV-2.jpg

* Ortisa. (2010, 19 de marzo). Scheme TEM.es.png [esquema de un microscopio electrónico de transmisión]. https://commons.wikimedia.org/wiki/File:Scheme_ TEM.es.png

* Rober, M. (2020, 18 de marzo). How To See Germs Spread Experiment (Coronavirus) [video]. YouTube. https://youtu.be//5-dl74zxPg 
* RCSBProteinDataBank. (2020, 18 de mayo). Fighting Coronavirus with Soap [video]. YouTube. https://youtu.be/s2EVlqql_f8

- U.S. National Library of Medicine. (2020, 20 de agosto). Temperatura corporal normal. Medline Plus. https://medlineplus.gov/spanish/ency/article/001982. htm\#: :text=Algunos\%20e

* Velavan, T. P. y Meyer, C. G. (2020, marzo). The covid-19 epidemic. Tropical Medicine and International Health, 25(3), 278-280. Dol: https://doi.org/10.1111/tmi.13383

*ölker, C. (2020, 20 de marzo). Keep your distance: A new video from the BauhausUniversität Weimar illustrates how germs can spread through the air. Bauhaus Universität Weimar. https://cutt.ly/dk2OtGo

Vox. (2020, 18 de marzo). How soap kills the coronavirus [video]. YouTube. https:// youtu.be/-LKVUarhtvE

* Winey, M., Meehl, J. B., O’Toole, E. T. y Giddings, T. H. Jr. (2014). Conventional transmission electron microscopy. Molecular biology of the cell, 25(3), 319-323. Dol: https://doi.org/10.1091/mbc.E12-12-0863

* Youtube pidc. (2020, 30 de junio). Face mask experiment [video]. YouTube. https:// www.youtube.com/watch?v=dcvdvZ16nlw

\section{Cómo CITAR ESTE ARTículo}

* Cerecedo Núñez, Héctor Hugo y Padilla Sosa, Patricia. (2021, marzo-abril). Física aplicada: apoyo al combate de la pandemia covid-19. Revista Digital Universitaria (RDU), 22(2). Dol: http://doi.org/10.22201/cuaieed.16076079e.2021.22.2.6 